\title{
Comparing Practice Between Working Standard and Personal Working Standard of Teachers Who Are Certified by Attending Professional Teacher Knowledge Standard Workshop
}

\author{
Songsak Phusee-orn ${ }^{1}$ \\ ${ }^{1}$ Faculty of Education, Mahasarakham University, Mahasarakham, Thailand \\ Correspondence: Songsak Phusee-orn, Faculty of Education, Mahasarakham University, Mahasarakham, \\ Thailand.
}

Received: May 15, 2021

doi:10.5539/ies.v14n9p69
Accepted: July 2, $2021 \quad$ Online Published: August 25, 2021

URL: https://doi.org/10.5539/ies.v14n9p69

\begin{abstract}
The purposes of this research are to compare the practice between working standard and personal working standard of teachers who are certified by attending professional teacher knowledge standard workshop held by the teachers' council who are different in gender, age, ways of knowledge certified and teaching according to/not according to educational certificate background. The samples are 246 research participants certified by attending professional teacher knowledge standard workshop of the teacher's council: Developmental division of the Faculty of Education, Mahasarakham University. Sampling operated by using Multi-Stage Random Sampling. Teachers' data collection are self-evaluation and with school directors also as informers. Research instrument are piloted quality inspected questionnaire indicated by Item Total Correlation and Reliability of Cronbach. Data are analyzed by using X, s.d., t-test: independent samples, One way ANOVA, and multiple comparison of Scheffe. The research found that:
\end{abstract}

1) Overall, the female teachers who have been certified by attending professional teacher knowledge standard workshop of the teacher's council follow teaching standard in the academic activities facets on professional teacher's development and self-practice standard and ethic is higher than male teachers with statistically significant at the .05 level.

2) Teachers who with age differences follow the standard of being a good role model for the students. They work cooperatively with others in the community creatively. Personal practice standard about ethic to society is different with statistically significant at the .05 level.

3) Teachers who have been certified by attending professional teacher knowledge standard workshop of the teacher's council foster on teacher professional development and immensely develop the students to their full potential more than transferring method with statistically significant at the .05 level.

4) Teachers who teach according to educational certificate background practice according to the standard professional teacher on designing learning activities with the students in mind. They thrive so as to make every opportunity to be for learning. They also have higher ethic than teachers who are not teaching according to their educational certificate background with statistically significant at the .05 level.

Keywords: working standard, personal working standard, professional teacher knowledge standard

\section{Introduction}

Being a teacher is honorary and very important because teachers influence the dynamic of the society by developing the youth and people of the nation. The occupation brave the chance to teach the pupils to grow up to become educated, both knowledge-wise and morality-wise. Moreover, teachers build the nation to achieve its goals by being a role model, both intellectually and in behavior. They create youth of the nation to be good, lead, establish and develop morality and value to the society. They lead and support the religion and culture, create and develop the pupil in the righteous direction. All in all, teachers are the true influencer in developing education, society, economics, politics and governization.

Another importance of being a teacher is the code of honor of the occupation which every teacher have that are being a good model, merciful to the pupils, proud of the occupation they hold, never stop learning, have 
responsibility, adaptable to changes, solitarily have service mind. Teachers have to be knowledgeable in their area of teaching, be good in managing, and have general knowledge and psychology. They also have to nurture culture and environment. Most importantly, they must possess the ability to teach and develop leadership, cooperate by suitable means to create skills till they become habits. These qualities coincide with Phinyo et al. (2016) which found that besides developing the teachers bearing mind service and good team work, there still morality and standards to be achieved. This go in line with (SEAME INNOTECH, 2014) which support the quality of the $21^{\text {st }}$ century teachers in South East Asia which teachers not only are knowledgeable and skillful in their craft but got to have good personality and develop themselves continually as skillful and lifelong learning.

To support these mentions, Thailand have teacher's council which act as a council for teachers and have involved in education established by the Royal Act of teacher's council and educational staff in 2003. Their roles are to hold occupational standard, register and withdraw teaching license, monitor to uphold the standard of teaching and ethics and develop to higher the standard of the occupation.

From the rules of the teacher's council in 2013, there are many standards applied, especially the fact that teachers must have knowledge and occupational experience, working standard and practice standard. The knowledge and experience are rules of knowledge and teaching experience which those in teaching occupation must have in order to teach. Teaching practice standards are rules concerning the characteristics or ways of action on operating and developing the occupation which those involves in education must follow to match the purposes and goals of learning in education management to also practice to obtain skills or expertized continually. Practice standard is ethics of the occupation which established according to the protocols of behavior which those involved in education must follow to maintain and hold the honor, the reputation and the status of those involved in education to gain pride which the society will further the pride and dignity of the profession.

Other importance are the license to teach which means the license which are registered for teachers whose main profession is to teach and support learning of the pupils in various ways in institution of child care, primary and college levels which are under diploma both belonging to the government and private sectors. Ways to be qualified to get the teaching license which all share the purpose of screening for teachers who are professional. This is because the quality of the teachers is the major effect to the pupils' learning outcome (OECD 2005; Barber and Mourshed, 2007). One way is to attend the workshop held by the teacher's council which is held at university institute to develop the teachers at the Faculty of Education, Mahasarakham University to educate the teaching practice standard and the personal standard to observe the characteristics if they stand up to the standard and the factors effecting it which are gender, age, ways of certified and teaching matching/not matching educational certification which effect teachers, standards in which perspective to be the resources in developing teaching qualities and professions.

\section{Method}

\subsection{The Research Population}

Population is 908 teachers who are certified by attending professional teacher knowledge standard workshop held by the teachers' council: Developmental division of the Faculty of Education, Mahasarakham University with at least one standard and are still teaching.

\subsection{The Research Participants}

Participants are 246 teachers who are certified by attending professional teacher knowledge standard workshop held by the teachers' council: Developmental division of the Faculty of Education, Mahasarakham University and are still teaching. They are selected by Multi-Stage Random Sampling. Data collection is done by self-evaluation and with school directors also as informers.

\subsection{The Study Variable Factor}

Dependent variables are the practice of 12 working standards and 5 personal working standards.

Independent variables are gender (male, female), age (not more than 30, 31 to 40 and above 40), ways of certified (transfer, attending workshop) and teaching matching/not matching educational certified.

\subsection{Research Instrument/Data Collection Methodology}

The researcher uses piloted quality inspected questionnaire to try on 23 teachers who are certified by attending professional teacher knowledge standard workshop held by the teachers' council: Developmental division of the Faculty of Education, Mahasarakham University. The data is analyzed by using Item total correlation and reliability of Cronbach by analyzing the quality of: 12 working standards with 36 questions found that discrimination between .316 and .823 . The reliability is .948 and 5 personal working standards with 13 questions 
found that discrimination between .219 and .824 . The reliability is .893

\subsection{Data Collection}

The researcher collects the data by checking the data primarily with Developmental division of the Faculty of Education, Mahasarakham University and by telephone to inform that questionnaire will be sent and return by mail.

\subsection{Data Analysis Method}

To compare the practice between working standard and personal working standard of teachers who are certified by attending professional teacher knowledge standard workshop held by the teachers' council who are different in gender, ways of knowledge certified and teaching according to/not according to educational certificate background by using independent samples of t-test

To compare the practice between working standard and personal working standard of teachers who are certified by attending professional teacher knowledge standard workshop held by the teachers' council who are different in age by using One way ANOVA and Multiple comparison of Scheffe

\section{Results}

The researcher has divided presenting 4 parts of data analysis results according to the variables as follows:

1) The comparison results of teachers who are certified by attending professional teacher knowledge standard workshop held by the teachers' council who are different in gender has found no differences. When analyzed in different facet, it was found that 2 facet were different which are academic operation of teacher professional development and the moral of those using the service as shown in Table 1.

Table 1. The results of comparing between working standard and personal working standard by gender

\begin{tabular}{lccccc}
\hline Standard & gender & Mean & S.D & t-value & Sig \\
\hline Working standard & male & 4.01 & .62 & \multirow{2}{*}{$2.74 *$} & \multirow{2}{*}{.007} \\
Attending activities to develop Professionally & female & 4.24 & .59 & & \\
Personal working standard & male & 4.75 & .37 & \multirow{2}{*}{$2.03^{*}$} & \multirow{2}{*}{.044} \\
Moral of teaching & female & 4.84 & .29 & & \\
\hline
\end{tabular}

Note. $* \mathrm{p}<.05$; It was found that the female teachers who are certified by attending professional teacher knowledge standard workshop held by the teachers' council attended more activities to develop professionally with moral in teaching more than the male teachers with statistic significant .05.There is no difference in other facets.

2) The comparison results of teachers who are certified by attending professional teacher knowledge standard workshop held by the teachers' council who are different in age found that there is no difference in teaching. When examining different facets, it was found that there are 3 differences. They are being a good role model to the students, creatively joining the community and morality to the society as shown in Table 2 .

Table 2. The results of comparing between working standard and personal working standard by age

\begin{tabular}{lccccccc}
\hline Standard & SOV & SS & df & MS & F & Sig & Post Hoc \\
\hline \multirow{2}{*}{ Working standard } & Between Groups & 1.15 & 2 & .577 & & & \\
Being a role model to the students & Within Groups & 39.03 & 243 & .161 & $3.59^{*}$ & .029 & $2>1$ \\
& Total & 40.18 & 245 & - & & & \\
& Between Groups & 1.52 & 2 & .762 & & & \\
Creatively joining the community & Within Groups & 44.04 & 243 & .181 & $4.20^{*}$ & .016 & $2>3$ \\
& Total & 45.57 & 245 & - & & & \\
Personal working standard & Between Groups & 1.11 & 2 & .553 & & & \\
Morality to the society & Within Groups & 39.73 & 243 & .164 & $3.38^{*}$ & .036 & $2>1$ \\
& Total & 40.84 & 245 & - & & & \\
\hline
\end{tabular}

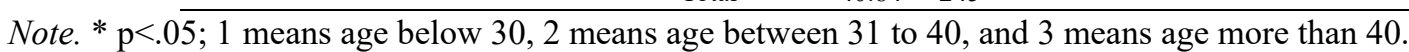

From Table 2, it was found that the teachers who are certified by attending professional teacher knowledge standard workshop held by the teachers' council with different age gap are different in being a good role model to 
the students, creatively joining the community and morality to the society with statistic significant .05 . The teacher age between 31 and 40 is higher than those ages not more than 30 in being a role model to the student have morality to the society. The group also ranked higher in creatively joining the community than those who are more than 40 with no difference in other facets.

3) The comparison results of teachers who have been certified by attending professional teacher knowledge standard workshop of the teacher's council categorized by certification found that teachers who have been certified by attending professional teacher knowledge standard workshop of the teacher's council who are differently certified are no different. When examine in facets, two are different. They are continual professional development and thriving to let the students learn to their full potential as shown in Table 3.

Table 3. The results of comparison between working standard and personal working standard differentiated by methods of qualification

\begin{tabular}{lccccc}
\hline Standard & methods of qualification & Mean & S.D & t-value & Sig \\
\hline Working standard & transfer & 4.04 & .62 & \multirow{2}{*}{$2.35^{*}$} & .010 \\
Continual professional development & workshop & 4.23 & .60 & & \\
\multirow{2}{*}{ Thriving to let the students learn to their full potential } & transfer & 4.46 & .36 & \multirow{2}{*}{$.90^{*}$} & .029 \\
& workshop & 4.57 & .43 & & \\
\hline
\end{tabular}

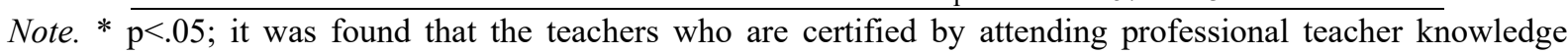
standard workshop held by the teachers' council who attend workshop for continual professional development and thriving to let the students learn to their full potential have statistic significant .05 and have no difference in other facets.

4) The comparison results of teachers who have been certified by attending professional teacher knowledge standard workshop of the teacher's council categorized by those who certified and teaching matching/not matching educational certification found that there are no different between the two. When examining in each facets, it was found that there are 4 which are different. They are continual professional development, creating activities with the learners' interest in mind, looking for every opportunity for the learners to learn and have moral as shown in Table 4.

Table 4. The comparison results of working standard and personal working standard categorized by those who certified and teaching matching/not matching educational certification

\begin{tabular}{lccccc}
\hline Standard & matching/not matching & Mean & S.D & t-value & Sig \\
\hline Working standards & matching & 4.19 & .59 & \multirow{2}{*}{$1.69^{*}$} & \multirow{2}{*}{.046} \\
continual professional development & not matching & 4.02 & .61 & & \\
& matching & 4.74 & .39 & \multirow{2}{*}{$1.82^{*}$} & .037 \\
creating activities with the learners' interest in mind & not matching & 4.59 & .51 & & \\
& matching & 4.39 & .49 & \multirow{2}{*}{$1.83^{*}$} & .035 \\
looking for every opportunity for the learners to learn & not matching & 4.27 & .43 & & \\
Personal working standard & matching & 4.77 & .39 & \multirow{2}{*}{$1.73^{*}$} & .044 \\
having morality & not matching & 4.62 & .58 & & \\
\hline
\end{tabular}

Note. $* \mathrm{p}<.05$; Teachers who have been certified by attending professional teacher knowledge standard workshop of the teacher's council categorized by those who certified and teaching matching educational certification found that they continually develop professionally, create activities with the learners' interest in mind and looking for every opportunity for the learners to learn and have personal working standard in having moral higher than teachers who certified and teaching and not matching educational certification potential have statistic significant .05 and have no difference in other facets.

\section{Discussion}

1) Overall, the female teachers who have been certified by attending professional teacher knowledge standard workshop of the teacher's council follow teaching standard in the academic activities facets on professional teacher's development and self-practice standard and ethic is higher than male teachers with statistic significant .05 . There is no difference in other facets. This may be because are more service minded than male 
teachers and have no problem in expressing them as well such as showing compassionate and mercy, taking care, supporting her pupils. Furthermore, it is found that female teachers have more drive to develop herself more than the male which coincide with (Chanasit, Maneera, \& Jiraro, 2016). They found that the will power to become a teacher divided by the gender - the female always takes over the male whether it is being merciful to the pupils, have good personality, good at transferring information, having service minded at the statistic significant .05. It's found that female teachers are more capable in managing the classroom to promote better learning at the statistic significant .05. (Chitkaew, 2016). This go in line with many studies in learning and teacher development, for example the teacher's background, workplace, the culture of the organization, leadership, and official and off the record support (Flores, 2004; Meirink et al., 2009; Avalos, 2011). The research results indicate that the teacher behavior correlated to the gender that they are because they have basic characteristics that are so different. Therefore, when planning on teacher development, this factor should be kept in mind to support where each gender needs lies.

2) Teachers who have been certified by attending professional teacher knowledge standard workshop of the teacher's council with age differences follow the standard of being a good role model for the students. They work cooperatively with others in the community creatively. Personal practice standard about ethic to society is different with statistic significant .05 . Teachers whose age are between 31 to 40 are better role model for the students and have better ethic towards society higher than teachers who aged below 30 . They work cooperatively with others in the community creatively. Personal practice standard about ethic to society is higher than teachers aged more than 40. There is no difference in other facets. This may be because younger teachers lack of expertise and experience to be a good model to the pupils such as having the leadership in reserving and developing the economics, society, religion, cultural arts, wisdom, environment which all need time to build upon. This shows that working experience effects lots of factors as (Manuela, H., 2013) has found that teaching experience are positively relatable to the outcome of teaching. These experiences are obtained through actual onsite teaching and are realized together with their co-workers. It quoted that innovative teacher needs to have the ability to communicate with the students from different backgrounds and cooperate with other colleagues (Pantic \& Wubbels, 2010). Therefore, it is crucial that newly recruited teachers have some old timer take them under their wing and be their advisors. It's found that mentoring within the first years of teaching is a means of providing more support to new teachers. (Ingersoll and Strong, 2011) New special educators who received social and emotional learning supports from their mentors within their first year of teaching reported greater job satisfaction and more positive thoughts on staying in the teaching profession as compared to those new teachers who did not receive the same support (Jaclyn, 2019). Pre-service teachers could not be knowledgeable about information literacy by taking a course. Rather, this knowledge only came from practicing these skills in classes and class assignments (Van Ingen \& Ariew, 2015; Anafo \& Filson, 2014). Noelle (2019) found that new teachers may struggle with modifying their practices and when something goes wrong. Possible solutions would be additional mentorship, observation of colleagues, and explicit room to fail, reflect, and try again which connects back to the school's culture and ethos. It's found that openness, conscientiousness, extraversion, and emotional stability of teachers were positively associated with teacher effectiveness, especially for evaluations of teaching. (Kim, Jorg, \& Klassen, 2019)

3) Teachers who have been certified by attending professional teacher knowledge standard workshop of the teacher's council foster on teacher professional development and immensely develop the students to their full potential more than transferring method with statistic significant .05.There is no difference in other facets. This may be the fact that workshops inspire learning. Regularly attending workshops help develop oneself continually which effect massively to the pupils' learning outcome. It's found that new teachers must be culturally responsive practitioners by receiving training to successfully teach in diverse schools and how to adapt pedagogical strategies to help diverse students achieve academically (Hope \& Naff, 2016). When new teachers receive training that incorporates the emotional competencies, their emotional competency scores tended to increase, as well as their teaching effectiveness (LeCates, 2019). Frazier (2018) found that there is a positive relationship between coaching and teacher competency. Teachers chose goals they believed would make a difference in their teaching practice and with their students. Because of this, those goals were relevant and meaningful to them, which is a key component of effective adult learning (Kearsley, 2010). It's also found that student success in school is influenced by teacher-student relationships. (Pianta, 1994)

4) Teachers who have been certified by attending professional teacher knowledge standard workshop of the teacher's council who teach according to educational certificate background practice according to the standard professional teacher on designing learning activities with the students in mind. They thrive so as to make every opportunity to be for learning. They also have higher ethic than teachers who are not teaching according to their educational certificate background with statistic significant .05 . There is no difference in other facets. This may be 
because when teachers teaching according to their qualification, because it is in their field of study, they are more likely to show their expertise. The more they teach, the more practice they get, which all the benefit falls on the students. Furthermore, it creates discipline, professional development, personality, and vision in developing the nation, economy, society, etc. also found that if greater job satisfaction and retention in the field leads to more effective teaching, then this will contribute to improving student achievement (Rockoff, 2008; Rand, 2012). Ali (Ali, A., 2019) found that teachers' who felt more confidence in having knowledge of students' culture discussed their efficacy with the students more positively. With teachers who have high levels of stress and burnout resulting in alarmingly high rates of teacher turnover which reveal that many teachers are not adequately prepared to teach (Hirshberg, 2017). Milton (2015) found that when considering the amount of time it takes teachers to prepare, plan, mark, participate in their school communities, and attempt to have a work-life balance, this 'overload' can act as a barrier to innovation. Khalifa (2016) states that the administrator's influence as a cultural leader must and will trickle down to the teachers' practices and mental models. A teacher's ability in affording every student a chance to advance academically hinged on full knowledge of culture and learning styles within the classroom (Day, 2014; Garcia \& Chun, 2016).

\section{Recommendation}

\subsection{Recommendations Applied from the Research}

1) Work place should encourage their teaching staff to have continual professional development especially with the male teachers who mostly transferred from qualifications not matching their qualification.

2) There should be workshop that promotes admiration, mercy, caring helping and supporting to the students, being a good role model in every aspects for male teachers.

3) There should be procedures in monitoring, looking after, checking teachers who are aged not more than 30 in the aspect of being a good role model for the students, for example the personality, the way they dress, and verbal and action suitable to be teachers.

\subsection{Recommendations for Future Research}

1) There should be qualitative studies in the context of why there are teachers being recruited to teach no matching their qualifications and how to solve this problem.

2) There should be studies to develop teachers who have been certified by attending professional teacher knowledge standard workshop of the teacher's council to be up to date like using online media.

3) There should be longitude studies on developing teachers who have been certified by attending professional teacher knowledge standard workshop of the teacher's council and study the obstacles which will lead to future development.

\section{Acknowledgments}

I would like to thank the Faculty of Education, Mahasarakham University to encourage and support this research. Thank you so much for the research samples and the experts who checked the quality of the tools. I would like to thank the students who helped in collecting the data. Finally, I would like to thank Asst. Prof. Dr. Sangrawee Donkaewbua and my colleagues for recommending the journal and manuscript preparation.

\section{References}

Ali, A. (2019). Understanding Relationships Between Cultural Competency And Teacher Efficacy. Wayne State University Dissertations. 2135. Retrieved from https://digitalcommons.wayne.edu/oa_dissertations/2135

Anafo, P., \& Filson, C. K. (2014). Promoting Information Literacy among Undergraduate Students of Ashesi University College, Ghana. Library Philosophy and Practice, 0-1. Retrieved from http://search.proquest.com/openview/1f20e6c9642078a40ccb8e944fd1a3b8/1?pqorigsite=gscholar\&cbl=54 903

Avalos, B. (2011). Teacher professional development in Teaching and Teacher Education over ten years. Teaching and Teacher Education, 27(1), 10-20. https://doi.org/10.1016/j.tate.2010.08.007

Barber, M., \& Mourshed, M. (2007). How the world's best performing school systems come out on top (McKinsey Report). Retrieved from http://www.mckinsey.com/App_Media/Reports/SSO/

Chanasit, D., Maneera, C., \& Jiraro, P. (2016). Spiritual teacher of the Faculty of Education Nakhon Pathom Rajabhat Universtiy. Silpakorn Education Research Journal, 8(1).

Chitkaew, J. (2016). Efficiency of Classroom Management by Teachers in Primary Schools under the Office of 
Private Education Promotion in Trang. Journal of southern technology, 9(1).

Day, S. (2014). Helping Educators Become Culturally Competent. Women in Higher Education, 23(10), 8.

Flores, M. A. (2004). The impact of school culture and leadership on new teachers' learning in the workplace. International Journal of Leadership in Education, 7(4), 297-318. https://doi.org/10.1080/1360312042000226918

Frazier, E. A. (2018). The impact of instructional coaching on teacher competency, job satisfaction, and student growth. A dissertation submitted to the Graduate Faculty of the University of Colorado.

Garcia, C., \& Chun, H. (2016). Culturally responsive teaching and teacher expectations for Latino middle school students. Journal of Latina/O Psychology, 4(3), 173-187. https://doi.org/10.1037/lat0000061

Hirshberg, M. J. (2017). Well-being training for preservice teachers. Retrieved from ProQuest Information \& Learning.

Hope, S., \& Naff, D. (2016). Cultural diversity professional development for teachers: A research brief. Retrieved from https://scholarscompass.vcu.edu/cgi/viewcontent.cgi7articleM 063\&context=mercpubs

Ingersoll, R., \& Strong, M. (2011). The impact of induction and mentoring programs for beginning teachers: A critical review of the research. https://doi.org/10.3102/0034654311403323

Jaclyn M. R. (2019). Can mentors and who teach social and emotional learning to new special educators enhance job satisfaction and retention? Perspective from new teachers and mentors. ST. John's University

Kearsley, G. (2010). Andragogy (M. Knowles). The theory into practice database. Retrieved from $\mathrm{http}$ :/elearning industry.com/the-adult-learning-theory-andragogy-ofmalcolm-knowles

Khalifa, M. (2016). Culturally Responsive School Leadership: A Synthesis of the Literature. Review of Educational Research, 86(4), 1272-1311. https://doi.org/10.3102/0034654316630383

LeCates, D. W. (2019). Emotional Competence and effectiveness of new teachers (Doctoral dissertation). Widener University.

Lisa, E. K., \& Verena, J., \& Robert, M. K. (2019). A Meta-Analysis of the Effects of Teacher Personality on Teacher Effectiveness and Burnout. Educational Psychology Review, 31, 163-195. https://doi.org/10.1007/s10648-018-9458-2

Manuela, H. (2013). Tomorrow's teachers-selecting the best: An exploration of the quality rationale behind academic and experiential selection criteria for initial teacher education programmes. Educational Assessment, Evaluation and Accountability, 25(2), 93-114. https://doi.org/10.1007/s11092-013-9162-1

Meirink, J. A., Meijer, P. C., Verloop, N., \& Bergen, T. C. M. (2009). How do teachers learn in The workplace? An examination of teacher learning activities. European Journal of Teacher Education, 32(3), 209-224. https://doi.org/10.1080/02619760802624096

Milton, P. (2015). Shifting Minds 3.0: Redefining the Learning Landscape in Canada.

Noelle, M. (2019). To the 21st Century, and beyond! Investgating the practical ways that secondary school teachers can develop the "21st Century competencies" in their students (Doctoral dissertation, University of Toronto).

OECD. (2005). Teachers matter: Attracting, developing and retaining effective teachers. Paris: OECD.

Pantic, N., \& Wubbels, T. (2010). Teacher competencies as a basis for teacher education-views of Serbian teachers and teacher educators. Teaching, 26(3), 694-703. https://doi.org/10.1016/j.tate.2009.10.005

Phinyo, S. et al. (2016). The Development of Strategies to Promotion for Teacher Competency of Municipality School. Journal of Humanities and Social Sciences University of Phayao, 4(1).

Pianta, R. (1994). Patterns of relationships between children and kindergarten teachers. Journal of School Psychology, 32, 15-32. https://doi.org/10.1016/0022-4405(94)90026-4

Rand. (2012). Teachers Matter: Understanding Teachers' Impact on Student Achievement. Santa Monica, Calif: RAND Corporation. Retrieved from https://www.rand.org/pubs/corporate_pubs/CP693zl-2012-09.html

Rockoff, J. (2008). Does mentoring reduce turnover and improve skills of new employees? Evidence from teachers in New York City.

SEAMEO INNOTECH. (2014). Teaching competency standards in Southeast Asian Countries. Retrieved from http://www.seameo.org/SEAMEOWeb2/imagesstories/Publications/Centerspub/2012TeachingCompetencyS 
tandards/Teaching CompetencyStd.pdf

Van Ingen, S., \& Ariew, S. (2015). Making the invisible visible: Preparing pre-service teachers for first steps in linking research to practice. Teaching and Teacher Education, 51, 182-190. https://doi.org/10.1016/j.tate.2015.07.001

\section{Copyrights}

Copyright for this article is retained by the author(s), with first publication rights granted to the journal.

This is an open-access article distributed under the terms and conditions of the Creative Commons Attribution license (http://creativecommons.org/licenses/by/4.0/). 